
Table 1. Recovery of AdULT Anopheles gambiae Giles from Larvas
PLACED IN PAPYRUS SWAMPS

\begin{tabular}{|c|c|c|c|c|c|}
\hline \multirow{2}{*}{$\begin{array}{l}\text { Exp. } \\
\text { No. }\end{array}$} & \multirow{2}{*}{$\begin{array}{l}\text { No. and stage (in } \\
\text { brackets) of larvæe }\end{array}$} & \multicolumn{2}{|c|}{$\begin{array}{c}\text { Days since larvæe } \\
\text { were placed in swamp }\end{array}$} & \multicolumn{2}{|c|}{$\begin{array}{l}\text { Total of adults } \\
\text { emerged }\end{array}$} \\
\hline & & $\begin{array}{c}\text { First } \\
\text { adult } \\
\text { emergence }\end{array}$ & $\begin{array}{c}\text { Last } \\
\text { adult } \\
\text { emergence }\end{array}$ & No. & $\begin{array}{l}\text { Per- } \\
\text { centage }\end{array}$ \\
\hline $\begin{array}{r}1 \\
3 \\
4 \\
5 \\
6 \\
10 \\
11\end{array}$ & $\begin{array}{l}140 \text { (I, II, III, IV) } \\
100 \text { (I) } \\
140 \text { (I, II, III, IV) } \\
140 \text { (I, II, III, IV) } \\
200 \text { (I, II, III, IV) } \\
200 \text { (IV) } \\
200 \text { (IV) }\end{array}$ & $\begin{array}{r}3 \\
26 \\
4 \\
3 \\
3 \\
3 \\
5\end{array}$ & $\begin{array}{r}20 \\
28 \\
23 \\
8 \\
9 \\
8\end{array}$ & $\begin{array}{r}30 \\
3 \\
1 \\
7 \\
12 \\
10 \\
7\end{array}$ & $\begin{array}{r}21 \cdot 4 \\
3 \cdot 0 \\
0 \cdot 7 \\
5 \cdot 0 \\
6 \cdot 0 \\
5 \cdot 0 \\
3 \cdot 5\end{array}$ \\
\hline
\end{tabular}

Totals : Larvæ, 1,120 ; adults emerged, 70 , that is, $6 \cdot 3$ per cent. (N.B. In column 2, the numbers are totals of all the respective stages shown.

did not complete their development to the adult stage. The detailed records indicate a very high mortality among the early stages. Generally, it would thus seem that the interior of papyrus swamps is extremely unfavourable for the development of A. gambiae larvæ. Also, the duration of the larva-adult period appeared to be considerably longer than one usually finds in the favoured natural breeding places.

The water in papyrus swamps is characterized by a very high degree of organic pollution and by extreme deoxygenation ${ }^{5,6}$. It has been suggested that suitable larval food is absent from swamp waters 7 and that the middle of the swamp does not provide breeding facilities for $A$. gambiae, owing to the high degree of organic pollution of the water which obtains there ${ }^{1}$. Several authors have directed attention to the absence of larvæ from water with large organic content ${ }^{8}$; although Harvey and Symes ${ }^{\circ}$ report to the contrary. It is also known that $A$. gambiae may tolerate a considerable degree of animal pollution, but it is very sensitive to organic pollution of vegetable origin ${ }^{3}$. Pollution in papyrus swamps is caused by decaying vegetation, and $A$. gambiae would thus be very sensitive to it. The view that an increase in the proportion of organic matter in natural breedingplaces slows down the development of $A$. gambiae larvæ ${ }^{10}$ is supported by the present observations. But, how far the predominantly anaerobic conditions of the swamp waters affected the results of our observations is not very clear. Since the larva depend on atmospheric air and are not forcibly prevented from periodically rising to the surface to breathe, lack of oxygen in the medium is not a respiratory problem. But it can influence the length of time during which the larva are submerged and this seems to be ecologically important.

L. K. H. (

Nuffield Swamp Research Scheme,

Department of Zoology,

Makerere University College, Kampala, Uganda.

1 Hopkins, ('. H. E., E. Afr, Med. J., 17, 189 (1940).

${ }^{2}$ Goma, L. K. H., Bull. Ent. Res., 51 (in the press).

"Muirhead-Thomson, R. C., "Mosquito Behaviour" (Arnold, 1951).

" Bates, M., "The Natural History of Mosquitoes" (Macmillan, 1949).

"Carter, G. S., "The Papyrus Swamps of Uganda" (Heffer, 1954).

- Beadle, L. C., J. Exp. Biol., 35, 556 (1958).

"Hancock, G. L. R., J. Anim. Ecol., 3, 204 (1934).

$\checkmark$ de Meillon, B., "The Anophelini of the Ethiopian (reographical Region", Pub. S, Afr. Inst. Med. Res., 10 (1947).

- Harvey, D., and Symes, C. B., Bull. Ent. Res., 22, 59 (1931). ${ }^{20}$ Holstein, M. H. " "Biology of Anopheles gambiae", W.H.O. Monogr.,
Taxonomic Significance of Spermathecal Structure in Some Species of Tribolium

RECENT examination of spermathece in tenebrionid beetles associated with stored products has revealed that there are two distinct types of structure which are termed here the 'tenebrio' type and the 'chamber' type. Their basic plan and relationship to the rest of the female reproductive system are similar; but there are certain differences which, in regard to the genus Tribolium, are considered to be of some phylogenetic significance. In both types, a duct of varying width and length, which terminates in the main sperm storage region, arises from the common oviduct. In Tenebrio molitor this duct is short and wide and ends in a group of convoluted, thin-walled. tubes bound together by a tough membrane. Arising from their common base is a single, longer structure which may be glandular, having large-celled walls and a restricted lumen. Dissection of fertilized females has shown that the convoluted tubes carry sperm. In the chamber type, found in Gnathocerus, Alphitobius, Alphitophagus and some Tribolium species, there is a similar duct which runs to a strongly chitinized chamber in which motile spermatozoa are easily detected. This is variously shaped and arising either from the end opposite the duct entrance or from the side is a more-or-less elongate glandular region. In Palorus species this basic pattern is modified, associated with a muscular bursa.

The genus Tribolium has been divided on external morphological features into five species groups, namely, brevicornis, confusum, alcine, castaneum and myrmecophilum, associated with the following geographical regions, America, Africa, Madagascar, Indo-Australia and the Malay peninsula and East Indies respectively ${ }^{1}$. The spermathecx of five species from the castaneum and confusum groups have recently been examined in some detail, and it was found that the structure in $T$. castaneum and madens (castaneum group) closely resembled that of Tenebrio whereas $T$. confusum, anaphe and destructor (confusum group) had the more common chamber type of spermatheca. In the former species the duct was very short, terminating in a number of long, convoluted tubes invested in a tough, elastic membrane. These tubes were found to contain spermatozoa. Connected to the common base of the tubes by a chitinized collar was a short, glandular region. In the latter species the duct was again short and wide, but terminated in a junction, one arm of which entered a strongly chitinized S-shaped chamber, while the other arm ran into a glandular region which was long in anaphe and destructor but shorter in confusum.

The present evidence supports the maintenance of the confusum (African) and castaneum (Indo-Australian) groups while further work is required to indicat $\theta$ similar associations between the other species groups mentioned here. Also, with regard to the suggestion that $T$. molitor and obscurus originated in Europe or Asia and were only later transported to Africa and America $^{2}$, possible affinities between the castanerm group and tenebrio species, and the evolutionary significance of the structures described here, must be considered.

\section{Gordon Surtems}

Pest Infestation Laboratory,

London Road, Slough, Bucks.

${ }^{1}$ Hinton, II. E., Bull. Ent. Res, 39, 13 (1948).

${ }^{2}$ Leclercq, J., Bull. Mus. Hist. Anat. Belge, 24, 1 (1948). 